\title{
Knowledge, attitudes, and practice behavior of dental hygienists regarding the impact of systemic diseases on oral health
}

Asma'a A. Faden, PhD, Anas B. Alsalhani, BDS, MSc, Majdy M. Idrees, BDS, MSc,

Mohammed A. Alshehri, BDS, Mohammad Z. Nassani, DDS, PhD, Omar B. Kujan, MSc, PhD.

\section{ABSTRACT}

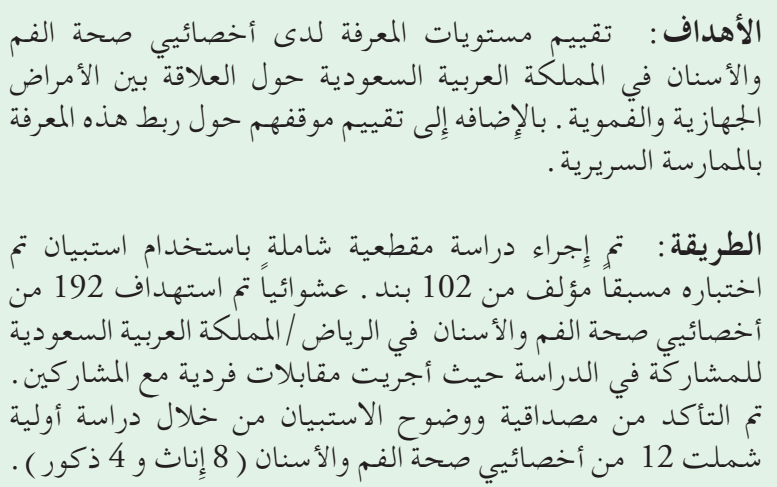

Objectives: To assess the knowledge levels of dental hygienists in Saudi Arabia regarding the association between systemic and oral disease in addition to evaluating their attitude about integrating this knowledge into clinical practice.
Methods: This was a cross-sectional survey using a questionnaire of 102 items among 192 randomly selected dental hygienists practicing in Riyadh, Saudi Arabia by individual interview. The research tool was pilot tested among 12 dental hygienists (8 females and 4 males) to obtain feedback about clarity and objectivity.

Results: The response rate was $83 \%$, and the majority of respondents were female (77.5\%). The respondents' knowledge about the risk factors of cardiovascular diseases was better than other conditions. The level of education was considered to be a significant predictor in many items related to risk factors. More than the half, rated the evidence linking periodontal disease and diabetes mellitus as strong; however, the knowledge level of oral-systemic evidence was less than expected. A high percentage of the respondents were confident and comfortable managing patients with systemic conditions. Most agreed that dental hygienists must be prepared efficiently to manage medically compromised patients.

Conclusion: Dental hygienists in Riyadh, Saudi Arabia have low level of knowledge about the oral-systemic disease relationship. This study suggests that greater emphasis should be placed on this association in current and continuing education programs.

Saudi Med J 2018; Vol. 39 (11): 1139-1147 doi: $10.15537 /$ smj.2018.11.23267

From the Department of Oral Medicine and Diagnostic Sciences (Faden), College of Dentistry; from the Department of Dental (Alshehri), College of Medicine and University Hospitals, King Saud University, from the Department of Oral Diagnostic Sciences (Salhani); from the Department of Prosthetic Dental Sciences (Nassani), Al-Farabi College for Dentistry and Nursing, Riyadh, Kingdom of Saudi Arabia, Private Dental Practice, (Idrees), Manama, Bahrain, and from the Department of Dental (Kujan), UWA Dental School, University of Western Australia, Nedlands, Australia.

Received 15th July 2018. Accepted 26th September 2018.

Address correspondence and reprint request to: Dr. Omar B. Kujan, Department of Dental, UWA Dental School, University of Western Australia, Nedlands, Australia. E-mail: omar.kujan@uwa.edu.au ORCID ID: orcid.org/0000-0002-5951-8280 
Tn the last decade, more emphasis had been placed 1 in dental practice on the importance of oral health as an essential part of overall health and well-being. ${ }^{1}$ Furthermore, the association between oral health especially periodontal status and systemic conditions had been well established. ${ }^{2,3}$ Generally, the term "oralsystemic link" is widely used to refer to the association between oral and systemic health. Remarkably, oral examination can reveal more than $90 \%$ of systemic diseases. ${ }^{1,4}$ Moreover, the World Health Organization International Classification of Diseases and Somatology currently lists more than 120 diseases that have oral cavity manifestations. ${ }^{5}$ Consequently, the term "the mouth is a mirror" has been widely used to illustrate the intimate relationship between systemic and oral health. ${ }^{4}$

Many preceding studies indicated a lack of knowledge regarding the oral-systemic evidence among workers in the medical field. ${ }^{6,7}$ A study in the United States of America, revealed that $49 \%$ of participant obstetricians rarely or never recommended a dental examination; furthermore, only $9 \%$ examine their patients 'mouth periodically. ${ }^{8}$ Another study among medical trainees and interns revealed that $90 \%$ of participants had never received any education about periodontal disease, and approximately $70 \%$ stated that they were not comfortable performing simple periodontal examinations.' Similarly, another study conducted among certified diabetes educators' (CDEs) in the United States of America demonstrated that oral health-related modules were not covered in the curricula of approximately $77 \%$ of participants. Furthermore, most respondents reported that they did not routinely provide oral health education to diabetic patients because of a lack of oral health knowledge. ${ }^{6}$ A survey of health professionals working in Riyadh, Kingdom of Saudi Arabia found that oral health knowledge among participants was poor. Fewer than $37 \%$ of participating medical doctors stated that dental plaque causes gingival inflammation. ${ }^{10}$

Thus, medical care providers in Riyadh, Kingdom of Saudi Arabia have limited oral health knowledge, and dental care providers have a greater responsibility in managing and predicting any oral-systemic disease complications. This is confirmed in a study by Forbes et $\mathrm{al}^{11}$ in which the authors recommend that dentists must be more involved in the management of patients with diabetes. Although dental practitioners are not

Disclosure. Authors have no conflict of interests, and the work was not supported or funded by any drug company. responsible for the diagnosis or treatment of systemic diseases, early detection will undoubtedly lead to better medical and dental outcomes. ${ }^{3,12}$

As the role of dentistry shifts from the diagnosis and treatment of carious teeth to include health promotion and education, knowledge of the oral-systemic disease association among oral health care providers is critical to achieve the aims of modern dentistry. Consequently, the responsibilities of oral health care providers have developed as well. One example of such a change over the last decades is in the dental hygiene profession. Previously, dental hygienists predominantly provided scaling and cleaning services. Today, the responsibilities of dental hygienists have expanded to include patient screening procedures, assessment of oral health conditions, oral cancer screening, and dietary counseling. ${ }^{13}$

While most previous studies assessed the knowledge and practices of dental practitioners regarding the association between systemic conditions and oral health, the role of dental hygienists was neglected..$^{14}$ Relatively few studies have been conducted to explore knowledge and attitude of oral hygienists regarding the oral-systemic disease association, moreover, a thorough review of the literature has revealed the absence of similar studies in the Middle East and North Africa. A survey among American dental hygienists in North Carolina, United States of America, revealed that the participants had incorporated some aspects of the oralsystemic evidence into their practice; however, 50\% were extremely likely to refer patients to a medical practitioner for follow-up. ${ }^{15}$ Another study in North Carolina, United States of America, found that dental hygienists had high knowledge level in some aspects of the oral-systemic disease association; further training was recommended in the areas of osteoporosis and pregnancy complications. ${ }^{14}$

The objectives of this study were to survey practicing oral hygienists in Riyadh, Kingdom of Saudi Arabia and to assess their knowledge regarding systemic diseases and related risk factors; assess their awareness regarding the association between periodontal disease and systemic conditions; and evaluate their attitude and behavior in clinical practice regarding the oral-systemic disease association.

Methods. Study design and data collection. The study consisted of a cross-sectional survey of 192 licensed dental hygienists practicing in either the public or private sector in Riyadh city, Kingdom of Saudi Arabia. The survey was conducted between January-April 2016. All procedures related to this survey were approved by 
the research and ethical committee of Al-Farabi College of Dentistry in Riyadh, Kingdom of Saudi Arabia and were in accordance with the principles of the Helsinki Declaration (IRB: OM; 0219). The survey was given out personally by 2 investigators to randomly selected dental hygienists. All participants were asked to sign an informed written consent prior to contribution.

Questionnaire development and description. The questionnaire was developed by the University of North Carolina at Chapel Hill, United States of America, to assess the knowledge, attitude, and behavior among dentists and dental hygienists in the United States of America regarding the oral-systemic disease relation when managing medically compromised patients. ${ }^{14,16}$ However, in order to assess the validity and reliability of the questionnaire in the Middle East region of the Kingdom of Saudi Arabia the questionnaire was pilot tested among 12 dental hygienists (8 females and 4 males) to obtain feedback about clarity and objectivity.

Demographic data were collected from all respondents including gender, age, working sector (either public or private), level of education (either 2 -year diploma or 4-year bachelor degree), and the number of working hours per week.

The survey questionnaire consisted of 102 items that were designed to induce either dichotomous or Likert-scale answers. Many sections were formulated in the survey to meet the objectives of the study, which comprised participants' demographics, scientific backgrounds, level of confidence, practice behavior, and finally opinions about previous training and collaboration with other specialties.

Data analysis. Data were analyzed using the Statistical Package for Social Sciences (SPSS) software version 22.0 (IBM Corp., Armonk, NY, USA). A Chi-squared test was used to check the association among the variables. Ordinal logistic regression analysis was performed to examine the role of gender, age, educational level, number of working hours per week, and working sector of the study participants as possible predictors for the subjects' responses. A $p$-value $<0.05$ was considered significant.

Results. One hundred and sixty subjects agreed to participate in the study out of 192 subjects that were initially interviewed (response rate 83\%); 124 females (77.5\%) and 36 males (22.5\%). The mean age of the study participants was $32.8 \pm 7.1$ years ranging between 21-59 years. The mean age of male subjects was $34.2 \pm 8.9$ years; for females it was $32.4 \pm 6.5$ years. The level of education (diploma or bachelor), nature of the working sector (public or private), in addition to the number of working hours per week of the study participants are shown in Table 1.

Table 2 lists the percentage of participants identifying 14 factors as risk factors for periodontitis, cardiovascular diseases (CVDs), diabetes mellitus (DM), pregnancy complications, and osteoporosis. A high percentage of the participants identified oral bacteria (93.6\%) as a risk factor for periodontitis followed by systemic inflammation (68.1\%). For CVDs, $95 \%$ of the participants identified high blood pressure as a risk factor followed by more than $86 \%$ for smoking and high cholesterol level. While $83.8 \%$ of participants cited diet as a risk factor for DM, only $68.7 \%$ stated physical inactivity as a risk. For pregnancy complications, just $63.8 \%$ of the participating subjects stated alcohol use was a risk factor followed by genetics (53.8\%). However, a smaller percentage of the respondents identified the risk factors for osteoporosis accurately ranging from less than 5\% for high cholesterol level to $46.9 \%$ for menopausal. Multiple regression analysis revealed that the level of education was significant in the relationship in 13 items (Table 3). In addition, gender was found to be significant predictors in 2 items; the working sector was a significant predictor in just one item (Table 3).

The participants' opinions about the strength of evidence linking periodontal diseases to 6 different systemic conditions are illustrated in Figure 1. More than half of the respondents $(51.9 \%)$ rated the evidence linking DM and periodontal disease as strong. About a fifth of the study participants stated that the link between pregnancy and osteoporosis with periodontal disease is strong. At the same time, 17\% reported that the evidence strongly linked periodontal disease with CVDs, followed by $13.2 \%$ for obesity. Finally,

Table 1 - Demographic and employment characteristics of dental hygienists.

\begin{tabular}{|c|c|c|c|c|}
\hline Characteristics & Male & $\begin{array}{r}\text { Female } \\
\mathrm{n}(\%)\end{array}$ & Total & $P$-value \\
\hline \multicolumn{5}{|l|}{ Employment sector } \\
\hline Public sector & $31(22.1)$ & $109(77.9)$ & $140(100)$ & \multirow{2}{*}{0.775} \\
\hline Private sector & $5(25.0)$ & $15(75.0)$ & $20(100)$ & \\
\hline \multicolumn{5}{|l|}{ Level of education } \\
\hline Diploma (2 years) & $20(26.3)$ & $56(73.7)$ & $76(100)$ & \multirow{2}{*}{0.272} \\
\hline Bachelor (4 years) & $16(19.0)$ & $68(81.0)$ & $84(100)$ & \\
\hline \multicolumn{5}{|l|}{ No. of working hours } \\
\hline 1-10 hours/week & $2(28.6)$ & $5(71.4)$ & $7(100)$ & \multirow{4}{*}{0.211} \\
\hline 11-20 hours/week & $8(40.0)$ & $12(60.0)$ & $20(100)$ & \\
\hline 21-30 hours/week & $11(21.6)$ & $40(78.4)$ & $51(100)$ & \\
\hline$>30$ hours/week & $15(18.3)$ & $67(81.7)$ & $82(100)$ & \\
\hline
\end{tabular}


Table 2 - Participants' responses about the risk factors of five different common conditions.

\begin{tabular}{lccccc}
\hline Risk factors & \multicolumn{4}{c}{ Disease/condition } \\
& Periodontitis & CVD & DM & $\begin{array}{c}\text { Pregnancy } \\
\text { complications }\end{array}$ & Osteoporosis \\
\hline Oral bacteria & $93.6^{*}$ & 55.0 & $38.7^{*}$ & $29.4^{*}$ & $11.3^{*}$ \\
Smoking & 48.7 & $86.3^{*}$ & $27.5^{*}$ & 49.4 & $15.6^{*}$ \\
Diabetes mellitus & $58.1^{*}$ & 51.9 & N/A & $37.5^{*}$ & 11.9 \\
Genetics & $31.9^{*}$ & $60.0^{*}$ & 48.1 & $53.8^{*}$ & $30.6^{*}$ \\
Systemic inflammation & $68.1^{*}$ & $61.3^{*}$ & 44.4 & $39.4^{*}$ & $37.5^{*}$ \\
Increased stress & 44.4 & $78.8^{*}$ & 43.1 & $39.3^{*}$ & $6.9^{*}$ \\
Alcohol use & 55.0 & $81.9^{*}$ & $60.0^{*}$ & $63.8^{*}$ & $30.0^{*}$ \\
Diet & 43.7 & $70.0^{*}$ & $83.8^{*}$ & 43.1 & $25.0^{*}$ \\
Race & $32.5^{*}$ & 47.5 & $36.9^{*}$ & $31.9^{*}$ & $20.6^{*}$ \\
Postmenopausal & $32.5^{*}$ & $30.0^{*}$ & $19.4^{*}$ & N/A & 46.9 \\
High blood pressure & $15.0^{*}$ & $95.0^{*}$ & $29.4^{*}$ & $34.4^{*}$ & $11.2^{*}$ \\
High cholesterol & $16.2^{*}$ & $86.9^{*}$ & $61.9^{*}$ & $23.1^{*}$ & $4.4^{*}$ \\
Obesity & $15.0^{*}$ & $65.0^{*}$ & $73.1^{*}$ & $23.7^{*}$ & $26.9^{*}$ \\
Physical inactivity & $16.9^{*}$ & $69.4^{*}$ & $68.7^{*}$ & $33.7^{*}$ & 43.7 \\
\hline *Significant relations by Chi-square $p<0.05$, CVD - cardiovascular diseases, DM - diabetes mellitus \\
\hline
\end{tabular}

Table 3 - The relationship between risk factors/diseases and significant determinants.

\begin{tabular}{|c|c|c|c|c|}
\hline Risk factor/disease & determinant & $\mathrm{B}(\mathrm{SE})$ & $95 \% \mathrm{CI}$ & $P$-value \\
\hline Genetics/CVD & \multirow{12}{*}{ Educational level } & $0.175(0.77)$ & $0.024-0.327$ & 0.024 \\
\hline Systemic inflammation/periodontitis & & $0.185(0.73)$ & $0.040-0.329$ & 0.012 \\
\hline Increase stress/CVD & & $0.145(0.06)$ & $0.018-0.272$ & 0.025 \\
\hline Alcohol use/CVD & & $0.165(0.06)$ & $0.046-0.284$ & 0.007 \\
\hline Alcohol use/osteoporosis & & $0.214(0.071)$ & $0.073-0.354$ & 0.003 \\
\hline Race/CVD & & $0.179(0.078)$ & $0.025-0.334$ & 0.023 \\
\hline Postmenopausal/CVD & & $0.209(0.071)$ & $0.069-0.349$ & 0.004 \\
\hline Postmenopausal/DM & & $0.154(0.062)$ & $0.032-0.277$ & 0.014 \\
\hline High cholesterol level/DM & & $0.233(0.076)$ & $0.083-0.382$ & 0.002 \\
\hline Obesity/osteoporosis & & $0.2(0.069)$ & $0.064-0.336$ & 0.004 \\
\hline Physical inactivity/DM & & $0.247(0.072)$ & $0.105-0.388$ & 0.001 \\
\hline Physical inactivity/osteoporosis & & $0.179(0.076)$ & $0.028-0.33$ & 0.02 \\
\hline Race/osteoporosis & Gender & $-0.278(0.074)$ & $(-0.424)-(-0.133)$ & 0.000 \\
\hline Alcohol use/pregnancy complications & Working sector & $-0.272(0.11)$ & $(-0.495)-(-0.049)$ & 0.017 \\
\hline
\end{tabular}

fewer than $10 \%$ of the respondents stated that there was strong evidence linking periodontal disease with respiratory diseases.

The dental hygienists' confidence and comfort level while managing patients with systemic conditions are shown in Table 4 . The respondents were slightly more comfortable asking patients about their smoking habits than their alcohol habits. In addition, participants were more comfortable treating periodontal patients who have diabetes $(82.7 \%)$ compared with periodontal patients with CVDs (73.7\%). Furthermore, they were less comfortable treating pregnant women with a higher risk of pregnancy complications or referring smokers to a smoking cessation clinic. More than $80 \%$ of the respondents felt confident discussing smoking cessation or the negative consequences of alcohol on the general health with their patients. Similarly, dental hygienists were consistently confident discussing the potential oral-systemic complications with patients who had periodontal disease, CVD, or diabetes or who were pregnant (range $75-80 \%$ ).

Table 5 shows the agreement level among the participants with statements regarding the inclusion of oral-systemic evidence in clinical practice. About three- 
quarters of participants either agreed or completely agreed that they thoroughly assess the patient's risk for systemic disease. Similarly, more than $73 \%$ of the participants agreed/completely agreed that they ask very detailed follow-up questions on the medical history form. More than $84 \%$ of the respondents agreed that they adjust the frequency of dental visits for patients with systemic conditions. A comparable proportion $(84.1 \%)$ stated that their knowledge about periodontal disease is current; consequently, $82.8 \%$ stated that they are interested in expanding their practice to include the management of patients with complicated medical conditions. Most participants (87.7\%) either completely agreed or agreed that they provide thorough

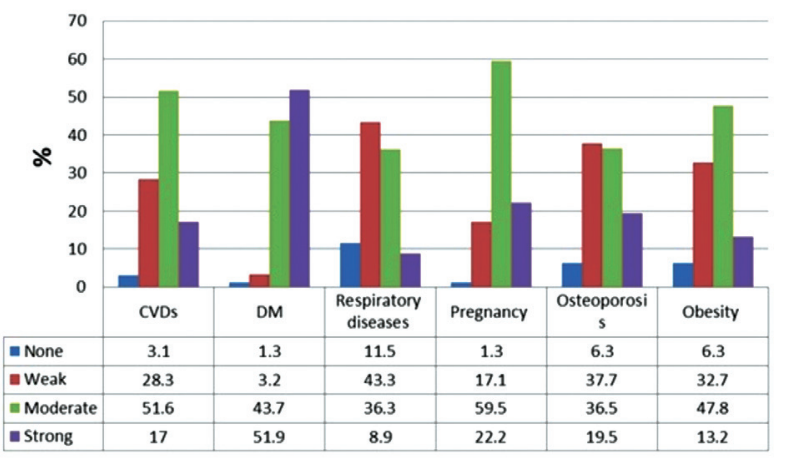

Figure 1 - The respondents' knowledge about the strength of evidence connecting periodontal disease with different systemic conditions by percentage of respondents to each item. CVD - cardiovascular diseases, DM - diabetes mellitus periodontal therapies to their patients. More than $82 \%$ of these dental hygienists agreed that their employers encourage staff members to incorporate evidence about oral-systemic disease into clinical practice.

The respondents' opinions about the professional training of dental hygienists, collaboration with other professions in the medical field, and patients' expectations are shown in Table 6. More than $80 \%$ agreed that dental hygienists must be trained efficiently to identify possible risk factors for oral-systemic diseases. Similarly, $87.2 \%$ of the participants agreed that both medical and dental professionals must be trained to practice in a more collaborative way. Regarding the collaboration between the dental and medical professions, most of the responding dental hygienists stated that medical providers must be trained to screen patients with periodontal diseases (84.6\%); more than $86 \%$ of the respondents agreed that medical providers have knowledge regarding the oral-systemic relations. Of these dental hygienists, approximately $84 \%$ stated that they were interested in collaborating more with physicians and nurses to improve patients' inter-professional care. Regarding patient expectations, approximately three-quarters of the participants reported that patients appreciate being asked more than $76 \%$ of the respondents reported that patients wanted them to take a more "active role" in the management of systemic conditions. Similarly, $76.4 \%$ of our study participants perceived that patients were asking more questions about oral-systemic relationships.

Table 4 - The comfort and confidence levels among the study participants regarding several areas of oral-systemic health.

\begin{tabular}{|c|c|c|c|c|}
\hline Statement & Respondents & $\begin{array}{l}\text { Completely } \\
\text { agree/agree }\end{array}$ & Neutral & $\begin{array}{c}\text { Completely } \\
\text { disagree/disagree }\end{array}$ \\
\hline \multicolumn{5}{|l|}{ I feel comfortable asking patients about: } \\
\hline Their alcohol habits & 128 & $69(53.9)$ & $25(19.5)$ & $34(26.6)$ \\
\hline Their tobacco habits & 124 & $75(60.5)$ & $29(23.4)$ & $20(16.1)$ \\
\hline \multicolumn{5}{|l|}{ Ifeel comfortable: } \\
\hline Referring patients who use tobacco to a smoking cessation clinic & 63 & $43(68.3)$ & $12(19.0)$ & $8(12.7)$ \\
\hline Treating patients who may be at risk for adverse pregnancy outcomes (PTLBW) & 155 & $103(66.5)$ & $34(21.9)$ & $18(11.6)$ \\
\hline Treating patients who have both CVDs and periodontal disease & 156 & $115(73.7)$ & $28(18.0)$ & $13(8.3)$ \\
\hline Treating patients who have both diabetes and periodontal disease & 156 & $129(82.7)$ & $20(12.8)$ & $7(4.5)$ \\
\hline \multicolumn{5}{|l|}{ I feel confident that I can counsel patients about: } \\
\hline The effects of alcohol on their oral-systemic health & 153 & $124(81.0)$ & $22(14.4)$ & $7(4.6)$ \\
\hline How to quit using tobacco & 153 & $123(80.4)$ & $22(14.4)$ & $8(5.2)$ \\
\hline \multicolumn{5}{|l|}{ I feel confident that I can discuss } \\
\hline Potential risks with pregnant patients who also have periodontal disease & 156 & $117(75.0)$ & $26(16.7)$ & $13(8.3)$ \\
\hline $\begin{array}{l}\text { Potential oral-systemic risks with cardiovascular patients who also have periodontal } \\
\text { disease }\end{array}$ & 156 & $117(75.0)$ & $26(16.7)$ & $13(8.3)$ \\
\hline Potential oral-systemic risks with diabetes who also have periodontal disease & 156 & $125(80.1)$ & $26(16.7)$ & $5(3.2)$ \\
\hline
\end{tabular}


Table 5 - Participants' level of agreement with statements regarding the inclusion of oral-systemic evidence in clinical practice.

\begin{tabular}{|c|c|c|c|c|}
\hline $\begin{array}{l}\text { To what extent do you agree with the following } \\
\text { statements? }\end{array}$ & Respondents & Completely agree/agree & $\begin{array}{l}\text { Neutral } \\
\text { n (\%) }\end{array}$ & Completely disagree/disagree \\
\hline $\begin{array}{l}\text { I ask very thorough/detailed follow up questions to "yes" } \\
\text { answers on the medical history form. }\end{array}$ & 155 & $114(73.6)$ & $23(14.8)$ & $18(11.6)$ \\
\hline $\begin{array}{l}\text { I thoroughly assess the patient's risk for systemic disease } \\
\text { as it relates to their oral condition. }\end{array}$ & 157 & $122(77.7)$ & $25(15.9)$ & $10(6.4)$ \\
\hline $\begin{array}{l}\text { I adjust the frequency of dental visits as needed for } \\
\text { patients with systemic conditions that might place them } \\
\text { at risk for oral-systemic complications. }\end{array}$ & 156 & $132(84.6)$ & $21(13.5)$ & $3(1.9)$ \\
\hline My knowledge about periodontal disease is current. & 157 & $132(84.1)$ & $19(12.1)$ & $6(3.8)$ \\
\hline $\begin{array}{l}\text { I provide thorough periodontal therapies to my patients } \\
\text { (scaling and root planning services, etc.). }\end{array}$ & 154 & $135(87.7)$ & $15(9.7)$ & $4(2.6)$ \\
\hline $\begin{array}{l}\text { My employer encourages staff members to incorporate } \\
\text { evidence about oral-systemic disease into clinical practice. }\end{array}$ & 156 & $128(82.1)$ & $18(11.5)$ & $10(6.4)$ \\
\hline $\begin{array}{l}\text { I am interested in expanding my practice to include } \\
\text { the management of patients with complicated medical } \\
\text { conditions. }\end{array}$ & 157 & $130(82.8)$ & $20(12.7)$ & $7(4.5)$ \\
\hline
\end{tabular}

The role of gender, age, educational level, number of working hours per week, and working sector of the study participants were assessed by ordinal logistic regression as significant predictors for participants' responses. However, none of these factors were a significant predictor.

Discussion. Participants were asked about the risk factors associated with 5 common conditions to assess their knowledge about systemic diseases. While most factors were strongly documented as risk factors for the listed conditions, the knowledge level among our participants was low.

Contrary to previous studies that documented a strong relationship between smoking and periodontitis (the odds ratio for developing periodontitis among smokers ranged between 2.5-7.28 fewer than the half of our respondents identified smoking as a risk factor for periodontitis). ${ }^{17-19}$ Similarly, obesity is the most common risk factor for pregnancy complications, but fewer than $25 \%$ of our participants accurately responded to this item. ${ }^{20,21}$

The level of awareness among the study participants was extremely low compared with other studies. A study of dental hygienists in North Carolina, United States of America, in 2012 revealed that more than $90 \%$ of the participants identified DM, smoking, and genetics as risk factors for periodontitis. In contrary, less than $60 \%$ of our participants stated that DM is a risk factor for periodontitis, followed by less than $50 \%$ for smoking and about $30 \%$ for genetics for our study subjects. ${ }^{14}$

At the same time, our findings revealed that respondents were less knowledgeable about the risk factors of osteoporosis and adverse pregnancy complications compared with other conditions. This is consistent with a study by Bell et al, ${ }^{14}$ that revealed similar findings.

Multivariate analysis revealed that the level of education has a significant impact on the participants' responses regarding specific items. In fact, bachelor degree holder's responded correctly to some items compared to diploma holders. This could be because of differences in their knowledge. Likewise, gender was a significant predictor when the respondents identified race as a risk factor for osteoporosis. This could be imputed to a higher knowledge level among the females compared to males in issues related to menopause. However, no significant difference between males and females was found regarding pregnancy. This may be attributed to the fact that pregnancy is a more common state, and both genders have attained same level of knowledge.

On the other hand, periodontal disease is considered the second most common disease affecting the oral cavity next to dental caries. ${ }^{22-24}$ Therefore, managing and treating patients with periodontal disease is a routine procedure in dental practice. ${ }^{25}$ In addition, periodontal disease has been identified as the body's most abundant source of chronic low-grade inflammation. ${ }^{26}$ This causes a decrease in the body's immune response, contributes to the total inflammatory burden of the body, and eventually causes irreversible damage to the immune system. ${ }^{26}$ Hence, all dental staff should be knowledgeable about factors related to periodontal disease such as 
Table 6 - Participants' level of agreement with statements regarding training, collaboration with other specialties, and patient expectations in clinical practice.

\begin{tabular}{|c|c|c|c|c|}
\hline To what extent do you agree with the following statements? & Respondents & $\begin{array}{l}\text { Completely agree/ } \\
\text { agree }\end{array}$ & $\begin{array}{l}\text { Neutral } \\
\text { n (\%) }\end{array}$ & $\begin{array}{l}\text { Completely disagree/ } \\
\text { disagree }\end{array}$ \\
\hline \multicolumn{5}{|l|}{ Training } \\
\hline $\begin{array}{l}\text { Dental hygienists should be trained to identify risk factors for } \\
\text { oral-systemic disease. }\end{array}$ & 156 & $130(83.3)$ & $19(12.2)$ & $7(4.5)$ \\
\hline $\begin{array}{l}\text { Dental hygienists should be trained to actively manage a patient } \\
\text { with systemic disease (e.g., diabetes, respiratory disease, CVD). }\end{array}$ & 156 & $125(80.1)$ & $11(7.1)$ & $20(12.8)$ \\
\hline $\begin{array}{l}\text { During their formal education, dental and medical professionals } \\
\text { should be taught to practice in a more collaborative way. }\end{array}$ & 156 & $136(87.2)$ & $14(9)$ & $6(3.8)$ \\
\hline \multicolumn{5}{|l|}{ Collaboration } \\
\hline $\begin{array}{l}\text { Medical providers should be trained to screen patients for } \\
\text { periodontal disease. }\end{array}$ & 156 & $132(84.6)$ & $15(9.6)$ & $9(5.8)$ \\
\hline $\begin{array}{l}\text { Medical colleagues would like for me to take a more active role } \\
\text { in the management of my patients' systemic health issues (e.g., } \\
\text { diabetes, respiratory disease, CVD). }\end{array}$ & 155 & $134(86.5)$ & $14(9)$ & $7(4.5)$ \\
\hline $\begin{array}{l}\text { Physicians and nurses in my area are knowledgeable about oral- } \\
\text { systemic connections. }\end{array}$ & 155 & $128(82.6)$ & $15(9.7)$ & $12(7.7)$ \\
\hline $\begin{array}{l}\text { I am interested in collaborating more with physicians and } \\
\text { nurses to improve interprofessional care of patients. }\end{array}$ & 155 & $130(83.9)$ & $20(12.9)$ & $5(3.2)$ \\
\hline \multicolumn{5}{|l|}{ Patient expectations } \\
\hline $\begin{array}{l}\text { My patients would like for me to take a more active role in the } \\
\text { management of their systemic health. }\end{array}$ & 157 & $120(76.4)$ & $26(16.6)$ & $11(7)$ \\
\hline $\begin{array}{l}\text { My patients appreciate it when I ask them questions about their } \\
\text { systemic health. }\end{array}$ & 157 & $115(73.3)$ & $31(19.7)$ & $11(7)$ \\
\hline $\begin{array}{l}\text { I have experienced an increase in the number of questions } \\
\text { patients ask me about oral-systemic relationships. }\end{array}$ & 157 & $120(76.4)$ & $18(11.5)$ & $19(12.1)$ \\
\hline
\end{tabular}

etiology, underlying pathological process, associated risk factors, and related negative impact on other tissues.

Our findings revealed that approximately 85\% of the respondents stated that their knowledge about periodontal-systemic interactions is current; similarly, most expressed that they provide comprehensive periodontal therapies to their patients. However, the knowledge-related items in our survey revealed that the level of awareness among them regarding the risk factors of periodontal disease was low in general. While approximately three-quarters of dentists and dental hygienists in previous studies stated that the link between periodontal disease and CVDs was strong and less than a fifth of our participants agreed with that. This study revealed a lack of knowledge among participants about the strength of evidence connecting periodontal disease with respiratory diseases, osteoporosis, and obesity. This agrees with the findings of other studies. ${ }^{14,16}$

More than three-quarters of our participants stated that they asked their patients thorough questions about their systemic health; in addition, more than $80 \%$ adjust the appointments of medically compromised patients to avoid possible complications. Therefore, despite the lack of knowledge among our study respondents, the respondents were aware of several precautions that must be considered while managing medically compromised patients.

Nevertheless, our findings revealed that most respondents were confident and comfortable managing medically compromised patients. Perhaps as a result of apprehension from serious medical complications or legal liability, the comfort level of respondents decreased from more than $80 \%$ when asked about DM to approximately $66 \%$ for pregnancy complications. Bell et $\mathrm{al},{ }^{15}$ identified the barriers of incorporating oral-systemic evidence into dental practice. The main barriers were lack of time (52\%), legal risks (44\%), and lack of education (27\%).

Our findings suggest that more education regarding systemic diseases is required for dental hygienists. This is similar to the recommendations of other studies. ${ }^{14,27}$ Interestingly, more than $82 \%$ of our study participants had a readiness to expand their practice to include management of medically compromised patients, which is considerably higher than the findings of other 
surveys. ${ }^{14,16}$ Furthermore, most of our respondents were aware of the importance of incorporating oral-systemic evidence into a daily dental practice; in addition, a high percentage of the participants agreed that dental and medical professionals should work in collaboration while managing medically compromised patients. This finding is consistent with the results of other studies. ${ }^{14,16,28}$

However, evidence suggests that inter-professional education directly reflects optimized healthcare services, strengthening medical systems, and improving health outcomes. ${ }^{29}$ Moreover, the Commission on Dental Accreditation in the United States of America requires preparation of dental hygiene graduates for inter-professional collaboration. ${ }^{30}$ Similarly, an editors' consensus report of the American Journal of Cardiology and Journal of Periodontology in 2009 stated that 'on the basis of current data, untreated or inadequately controlled moderate to severe periodontitis increases the systemic inflammatory burden, periodontitis may independently increase the risk of CVD's. ${ }^{31}$ Consequently, the consensus report endorsed that both dental and medical professionals should closely collaborate to optimize cardiovascular risk reduction and periodontal care. A recent study in 2017 revealed that inter-professional continuing education program among dental and non-dental health care professionals improved the oral-systemic health practice immediately. ${ }^{32}$

These findings are promising and suggest that the level of knowledge among the dental hygienists could be raised easily by training and education. Further training could be achieved in 3 ways: by revising college curriculums and incorporating topics about oralsystemic relations, by establishing specialized continuing education programs that focus on the oral-systemic evidence, and by enhancing the inter-professional collaboration between the health professionals to enable an interdisciplinary sharing of expertise, perspectives, and resources.

Study limitations. The study enrolled many dental hygienists practicing in Kingdom of Saudi Arabia and especially Riyadh, which is inconclusive. Another limitation is related to generalizability, the distribution of the survey was limited to Riyadh, which is the capital and the first most populous city in Kingdom of Saudi Arabia. Thus, it is difficult to generalize our findings to all dental hygienists in Kingdom of Saudi Arabia. Another study limitation was the survey did not ask about the barriers that deterred respondents from incorporating oral-systemic evidence into their practice.
In conclusion, Dental hygienists in Riyadh, Kingdom of Saudi Arabia demonstrated low level of knowledge and awareness regarding the oral-systemic evidence. Dental hygienists were confident and showed a desire to be engaged in the management of medically compromised patients. They appreciated the collaboration with medical professionals. However, comprehensive educational programs regarding the oral-systemic evidence must be established to promote the role of dental hygienists in the community.

Acknowledgment. The authors would like to thank Mr. Joseph Raheb, Sessional academic, Oral Health Therapy, School of Pharmacy and Biomedical Sciences, Faculty of Health Sciences, Curtin University, for his valuable remarks and feedback on the manuscript.

\section{References}

1. Klotz AL, Tauber B, Schubert AL, Hassel AJ, Schröder J, Wahl $\mathrm{HW}$, et al. Oral health-related quality of life as a predictor of subjective well-being among older adults-A decade-long longitudinal cohort study. Community Dent Oral Epidemiol 2018; doi: 10.1111/cdoe.12416.

2. Kim J, Amar S. Periodontal disease and systemic conditions: a bidirectional relationship. Odontology 2006; 94: 10-21.

3. Yonel Z, Sharma P. The Role of the Dental Team in the Prevention of Systemic Disease: the Importance of Considering Oral Health As Part of Overall Health. Prim Dent J 2017; 6: 24-27.

4. Oral Health in America. A report of the Surgeon General. $J$ Calif Dent Assoc 2000; 28: 685-695.

5. World Health Organization. Application of the International Classification of diseases to dentistry and stomatology: ICD-DA. 3rd ed. Geneva: WHO; 1995.

6. Yuen HK, Onicescu G, Hill EG, Jenkins C. A survey of oral health education provided by certified diabetes educators. Diabetes Res Clin Pract 2010; 88: 48-55.

7. Lewis CW, Grossman DC, Domoto PK, Deyo RA. The role of the pediatrician in the oral health of children: A national survey. Pediatrics 2000; 106: E84.

8. Wilder R, Robinson C, Jared HL, Lieff S, Boggess K. Obstetricians' knowledge and practice behaviors concerning periodontal health and preterm delivery and low birth weight. J Dent Hyg 2007; 81: 81.

9. Quijano A, Shah AJ, Schwarcz AI, Lalla E, Ostfeld RJ. Knowledge and orientations of internal medicine trainees toward periodontal disease. J Periodontol 2010; 81: 359-363.

10. Baseer MA, Alenazy MS, Alasqah M, Algabbani M, Mehkari A. Oral health knowledge, attitude and practices among health professionals in King Fahad Medical City, Riyadh. Dent Res J (Isfahan) 2012; 9: 386-392.

11. Forbes K, Thomson WM, Kunzel C, Lalla E, Lamster IB. Management of patients with diabetes by general dentists in New Zealand. J Periodontol 2008; 79: 1401-1408.

12. Ali D, Kunzel C. Diabetes mellitus: update and relevance for dentistry. Dent Today 2011; 30: 45-46, 48-50; quiz 51.

13. American Dental Hygienists Association [Internet]. Standards for clinical dental hygiene practice, 2016. [cited 2017 Nov 25] Available from: https://www.adha.org/resources-docs/2016Revised-Standards-for-Clinical-Dental-Hygiene-Practice.pdf 
14. Bell KP, Phillips C, Paquette DW, Offenbacher S, Wilder RS. Dental hygienists' knowledge and opinions of oral-systemic connections: implications for education. J Dent Educ 2012; 76: 682-694.

15. Bell KP, Phillips C, Paquette DW, Offenbacher S, Wilder RS. Incorporating oral-systemic evidence into patient care: practice behaviors and barriers of North Carolina dental hygienists. $J$ Dent Hyg 2011; 85: 99-113.

16. Paquette DW, Bell KP, Phillips C, Offenbacher S, Wilder RS. Dentists' knowledge and opinions of oral-systemic disease relationships: relevance to patient care and education. J Dent Educ 2015; 79: 626-635.

17. Bergström J. Cigarette smoking as risk factor in chronic periodontal disease. Community Dent Oral Epidemiol 1989; 17: 245-247.

18. Tomar SL, Asma S. Smoking-attributable periodontitis in the United States: findings from NHANES III. National Health and Nutrition Examination Survey. J Periodontol 2000; 71: 743-751.

19. Grossi SG, Genco RJ, Machtei EE, Ho AW, Koch G, Dunford $\mathrm{R}$, et al. Assessment of risk for periodontal disease. II. Risk indicators for alveolar bone loss. J Periodontol 1995; 66: 23-29.

20. Fitzsimons KJ, Modder J, Greer IA. Obesity in pregnancy: risks and management. Obstet Med 2009; 2: 52-62.

21. Leddy MA, Power ML, Schulkin J. The impact of maternal obesity on maternal and fetal health. Rev Obstet Gynecol 2008; 1: 170-178.

22. Burt B; Research, Science and Therapy Committee of the American Academy of Periodontology. Position paper: epidemiology of periodontal diseases. J Periodontol 2005; 76 : 1406-1419.

23. Petersen PE. The World Oral Health Report 2003: continuous improvement of oral health in the 21 st century--the approach of the WHO Global Oral Health Programme. Community Dent Oral Epidemiol 2003; 31: 3-23.
24. Idrees M, Hammad M, Faden A, Kujan O. Influence of body mass index on severity of dental caries: cross-sectional study in healthy adults. Ann Saudi Med 2017; 37: 444-448.

25. Idrees MM, Azzeghaiby SN, Hammad MM, Kujan OB. Prevalence and severity of plaque-induced gingivitis in a Saudi adult population. Saudi Med J 2014; 35: 1373-1377.

26. El-Shinnawi U, Soory M. Associations between periodontitis and systemic inflammatory diseases: response to treatment. Recent Pat Endocr Metab Immune Drug Discov 2013; 7: 169-188.

27. Boyd LD, Hartman-Cunningham ML. Survey of diabetes knowledge and practices of dental hygienists. J Dent Hyg 2008; 82: 43.

28. Nash WA, Hall LA, Lee Ridner S, Hayden D, Mayfield T, Firriolo J, et al. Evaluation of an interprofessional education program for advanced practice nursing and dental students: The oral-systemic health connection. Nurse Educ Today 2018; 66: 25-32.

29. Gilbert JH, Yan J, Hoffman SJ. A WHO report: framework for action on interprofessional education and collaborative practice. J Allied Health 2010; 39: 196-197.

30. Gaston MA. Revision of accreditation standards for dental hygiene education programs. J Dent Hyg 1998; 72: 24.

31. Friedewald VE, Kornman KS, Beck JD, Genco R, Goldfine A, Libby P, et al. The American Journal of Cardiology and Journal of Periodontology Editors' Consensus: periodontitis and atherosclerotic cardiovascular disease. Am J Cardiol 2009; 104: 59-68.

32. Mowat S, Hein C, Walsh T, MacDonald L, Grymonpre R, Sisler J. Changing Health Professionals' Attitudes and Practice Behaviors Through Interprofessional Continuing Education in Oral-Systemic Health. J Dent Educ 2017; 81: 1421-1429. 